\title{
Clinical effect of a positive surgical margin after hepatectomy on survival of patients with intrahepatic cholangiocarcinoma
}

This article was published in the following Dove Press journal:

Drug Design, Development and Therapy

17 December 2014

Number of times this article has been viewed

\author{
Chun-Nan Yeh' \\ Feng-Jen Hsieh' \\ Kun-Chun Chiang' \\ Jen-Shi Chen ${ }^{2}$ \\ Ta-Sen Yeh' \\ Yi-Yin Jan' \\ Miin-Fu Chen' \\ 'Department of General Surgery, \\ ${ }^{2}$ Department of Medical Oncology, \\ Chang Gung Memorial Hospital, \\ Chang Gung University, Taoyuan, \\ Taiwan
}

Background: Several unfavorable prognostic factors have been proposed for peripheral cholangiocarcinoma (PCC) in patients undergoing hepatectomy, including gross type of tumor, vascular invasion, lymph node metastasis, a high carbohydrate antigen 19-9 level, and a positive resection margin. However, the clinical effect of a positive surgical margin on the survival of patients with PCC after hepatectomy still needs to be clarified due to conflicting results.

Methods: A total of 224 PCC patients who underwent hepatic resection with curative intent between 1977 and 2007 were retrospectively reviewed. Eighty-nine patients had a positive resection margin, with 62 having a microscopically positive margin and 27 a grossly positive margin (R2). The clinicopathological features, outcomes, and recurrence pattern were compared with patients with curative hepatectomy.

Results: PCC patients with hepatolithiasis, periductal infiltrative or periductal infiltrative mixed with mass-forming growth, higher $\mathrm{T}$ stage, and more advanced stage tended to have higher positive resection margin rates after hepatectomy. PCC patients who underwent curative hepatectomy had a significantly higher survival rate than did those with a positive surgical margin. When PCC patients underwent hepatectomy with a positive resection margin, the histological grade of the tumor, nodal positivity, and chemotherapy significantly affected overall survival. Locoregional recurrence was the most common pattern of recurrence.

Conclusion: A positive resection margin had an unfavorable effect on overall survival in PCC patients undergoing hepatectomy. In these patients, the prognosis was determined by the biology of the tumor, including differentiation and nodal positivity, and chemotherapy increased overall survival.

Keywords: surgical margin, hepatectomy, cholangiocarcinoma

\section{Introduction}

Peripheral cholangiocarcinoma (PCC) is a malignant tumor of the liver, arising from the second or more distal branches of the intrahepatic bile ducts. ${ }^{1}$ The incidence of PCC varies widely in different regions, but generally accounts for $5 \%-30 \%$ of primary liver cancers. ${ }^{1}$ In a report from the Japan Liver Cancer Society, histologically proven PCC represented $3.58 \%$ of all primary liver cancers. ${ }^{1}$

Because of causative factors like liver flukes and hepatolithiasis, the incidence of PCC is ten times higher in Oriental countries. ${ }^{2-4}$ Due to its intrahepatic location, early symptoms are rare and most patients present with advanced tumors and have dismal survival. ${ }^{5,6}$ Hepatic resection provides the only chance of cure for PCC; however, most of the tumors are detected at an advanced stage, making curative resection challenging. ${ }^{6}$ In addition, there are no definitive guidelines for adjuvant chemotherapy or radiotherapy, leaving PCC patients with few treatment options. ${ }^{7-9}$ Although liver 
transplantation represents a possible alternative, high recurrence rates and a shortage of organs make this an unsuitable choice of treatment. ${ }^{10-12}$

Several unfavorable prognostic factors have been identified in PCC patients undergoing hepatectomy, including gross type of tumor, vascular invasion, lymph node metastasis, a high carbohydrate antigen 19-9 level, and a positive resection margin. ${ }^{13-18}$ We previously reported that an absence of physical findings, presence of mucobilia, an early-stage tumor, and curative resection were independent prognostic factors for long-term survival. ${ }^{19}$ Among these, the resection margin is the only factor that can be improved upon by hepatic surgeons. The presence of a positive resection margin varies from $15 \%$ to $68 \%$ in PCC cases. ${ }^{20-24}$ However, the impact of a positive surgical margin on PCC is conflicting. ${ }^{13-24}$ In this study, we investigated clinicopathological features and recurrence patterns in PCC patients who underwent hepatectomy with a positive resection margin and further clarified the effect of a positive resection margin (both gross and microscopic) on the prognosis.

\section{Materials and methods}

Between 1977 and 2007, 224 patients with histopathologically confirmed PCC underwent hepatic resection with curative intent at the Department of Surgery, Chang Gung Memorial Hospital, Taoyuan, Taiwan. This study retrospectively reviewed prospectively collected data for 224 (101 male and 123 female) patients with histologically confirmed PCC (adenocarcinoma), including 172 PCC patients with a non-intraductal papillary growth type and 52 PCC patients with an intraductal papillary growth type, who underwent hepatectomy. Curative resection was defined as a negative resection margin determined by histopathological examination. A positive resection margin was defined by either gross or histological examination. Tumors with a microscopically positive margin were defined as $\mathrm{R} 1$ and those with a grossly positive margin as R2. Among the 224 resected patients, $89(39.7 \%)$ had a positive margin. The clinicopathological features and outcomes were analyzed using patients with a negative margin for comparison. Tumors were evaluated before surgery by ultrasonography, computed tomography (CT) scanning, and magnetic resonance cholangiopancreatography as appropriate. Tumor stage was defined according to the 7th edition of the American Joint Committee on Cancer classification. Patients with lymph node metastasis and positive resection margins received adjuvant chemotherapy and/or radiotherapy. This retrospective study was approved by the institutional review board at Chang Gung Memorial Hospital (clinical study number 99-2886B).

\section{Follow-up}

Follow-up included physical examination, blood chemistry tests, and detection of tumor markers (carbohydrate antigen 19-9 and carcinoembryonic antigen) every 3 months. Abdominal ultrasonography was repeated at each visit. In the event of suspicious lesions on abdominal ultrasonography or elevated tumor markers, a comprehensive assessment for metastasis was done using CT or magnetic resonance imaging.

\section{Statistical analyses}

All data are presented as percentages of patients or as the mean and standard deviation. Numerical data were compared by analysis of variance tests. The Pearson's chi-square test and Fisher's Exact test were used for nominal variables. Multiple variance analysis of multinomial logistic regression test was used for multivariate analysis. The survival rate was calculated and plots were constructed using the KaplanMeier method, and data were compared between groups using the log-rank test. The Cox proportional hazards model was employed for multivariate regression analysis. Statistical Package for the Social Sciences version 13.0 software (SPSS Inc, Chicago, IL, USA) was used for the statistical analysis. $P \leq 0.05$ was considered to be statistically significant.

\section{Results}

\section{Demographic and clinicopathological data}

The distribution of operative procedures performed in the 224 PCC patients is shown in Table S1. Left hepatectomy was the most common operative procedure $(61.6 \%)$. Sixteen patients $(7.1 \%)$ underwent hepatectomy including caudate lobe resection. The liver parenchyma was the most common site of positive margin, followed by the bile duct and soft tissues (Table S2). Table 1 shows the demographic data, laboratory data, and pathological features of the 224 patients undergoing resection with negative (R0), microscopically positive (R1), and grossly positive (R2) margins. In total, there were 101 men and 123 women with a median age of 60 (range 22-89) years. Mucobilia was seen in 27 patients, and 95 had associated intrahepatic stones. A total of 52 patients had intraductal papillary tumor growth. Of the 224 patients who underwent resection, 89 had positive resection margins. Patients with a positive resection margin were further divided into R1 $(n=62)$ and R2 ( $=27)$ margins.

\section{Comparison of clinicopathological data in patients with R0, RI, and R2 resection margins}

The differences in clinicopathological characteristics between PCC patients with R0, R1, and R2 resection 
Table I Clinicopathological manifestation of intrahepatic cholangiocarcinoma 224 patients undergoing resection with negative, microscopically positive and grossly positive resection margins

\begin{tabular}{|c|c|c|c|c|}
\hline & $\begin{array}{l}\text { R0 } \\
(\mathrm{N}=135)\end{array}$ & $\begin{array}{l}R I \\
(N=62)\end{array}$ & $\begin{array}{l}R 2 \\
(\mathbf{N}=27)\end{array}$ & $P$-value \\
\hline Age (yrs) & 58.8 & 59.3 & 57.3 & 0.453 \\
\hline $\operatorname{Sex}(M / F)$ & $63 / 72$ & $25 / 37$ & $13 / 14$ & 0.668 \\
\hline CEA $(\mathrm{ng} / \mathrm{mL})$ & 3.8 & 4.4 & 4.2 & 0.526 \\
\hline CAI9-9 (U/mL) & 43.4 & 86.0 & 232.8 & 0.174 \\
\hline Size $(\mathrm{cm})$ & 5.0 & 5.0 & 5.7 & 0.057 \\
\hline Mucobilia & $17(12.6)$ & $6(9.7)$ & $4(14.8)$ & 0.755 \\
\hline IHD stones & $46(34.1)$ & $35(56.5)$ & $14(51.9)$ & 0.007 \\
\hline Gross type & & & & $<0.0001$ \\
\hline IP & $36(26.7)$ & $16(25.8)$ & $0(0.0)$ & \\
\hline MF & $57(42.2)$ & $17(27.4)$ & $5(18.5)$ & \\
\hline MF-PI & $16(11.9)$ & $12(19.4)$ & $12(44.4)$ & \\
\hline $\mathrm{PI}$ & $26(19.3)$ & $17(27.4)$ & $10(37.0)$ & \\
\hline Tumor number & & & & 0.542 \\
\hline Single & 117 (86.7) & $51(82.3)$ & $22(81.5)$ & \\
\hline Daughter or satellite & $13(9.6)$ & $5(8.1)$ & $3(I I . I)$ & \\
\hline Multiple & $5(3.7)$ & $6(9.7)$ & $2(7.4)$ & \\
\hline Tumor number & & & & 0.232 \\
\hline Single & $130(96.3)$ & $56(90.3)$ & $25(92.6)$ & \\
\hline Multiple & $5(3.7)$ & $6(9.7)$ & $2(7.4)$ & \\
\hline Histological grade & & & & 0.319 \\
\hline Well & $33(24.4)$ & $14(22.6)$ & $7(25.9)$ & \\
\hline Moderate & $52(38.5)$ & $22(35.5)$ & $8(29.6)$ & \\
\hline Poor & $34(25.2)$ & $14(22.6)$ & II (40.7) & \\
\hline Others & $16(11.9)$ & $12(19.4)$ & I (3.7) & \\
\hline T stage & & & & $<0.0001$ \\
\hline $\mathrm{TI} / \mathrm{T} 2$ & $74(54.8)$ & $16(25.8)$ & 0 & \\
\hline $\mathrm{T} 3 / \mathrm{T} 4$ & $61(45.2)$ & $46(74.2)$ & $27(100)$ & \\
\hline Nodal status & & & & 0.085 \\
\hline Negative & $108(80.0)$ & $43(69.4)$ & $17(63.0)$ & \\
\hline Positive & $27(20.0)$ & $19(30.6)$ & $10(37.0)$ & \\
\hline Staging & & & & $<0.0001$ \\
\hline $\mid / / I$ & $65(48.1)$ & $9(14.5)$ & 0 & \\
\hline III/IVA & 70 (5।.9) & $53(85.5)$ & $27(100.0)$ & \\
\hline
\end{tabular}

Abbreviations: yrs, years; $M$, male; $F$, female; $C A$, carbohydrate antigen; CEA, carcinoembryonic antigen; T, tumor; IHD, intrahepatic duct; IP, itra-ductal papillary; MF, mass-forming; MF-Pl, mass-forming mixed with periductal infiltrating; Pl, periductal infiltrating.

margins are shown in Table 1. The main differences between the three groups of patients were in tumor size, the rate of association with hepatolithiasis, gross tumor type, T stage, and disease staging. Larger tumor size, a positive association with hepatolithiasis, presence of periductal infiltrative growth, higher $\mathrm{T}$ stage, and advanced tumor staging were associated with a higher rate of positive resection margin.

However, further multivariate analysis using multinomial logistic regression revealed that PCC patients with R1 and $\mathrm{R} 2$ resection could be independently differentiated from those with $\mathrm{R} 0$ resection on the basis of a significantly higher rate of association with hepatolithiasis and advanced tumor staging (Tables S3 and S4).

\section{Prognostic factors for survival of patients with a positive surgical margin}

The duration of follow-up ranged from 1.12 to 95.90 months (median 7.36 months). Median survival for the resection group was 15.2 months and overall survival rates for 1, 3, and 5 years were $58.9 \%, 27.5 \%$, and $16.5 \%$, respectively. Among 224 PCC patients underwent hepatic resection with curative intent, including 135 patients with curative resection R0, R1 ( $n=62)$, and R2 ( $n=27)$. Nine patients who died within 1 month of surgery and one patient who was lost to follow-up were excluded from the analysis of survival rate. A total of 214 PCC patients with 130 curative resections were included in the survival analysis. Of 89 patients with positive surgical margins after resection, 62 had R1 and 27 had R2 margins. The survival analysis was performed for 84 patients (four patients were excluded because of perioperative mortality and one patient was lost to follow-up). Patients with a negative surgical margin $(n=130)$ had a median survival of 26.1 months and 1-year, 3-year, and 5-year overall survival of $78.5 \%, 43.3 \%$, and $28.6 \%$, respectively. However, patients ( $\mathrm{n}=84$ ) with an R1 margin and R2 margin had a median survival of 11.4 and 5.8 months, respectively, and 1-year, 3-year, and 5 -year overall survival of $47.5 \%, 6.8 \%$, and $4.5 \%$, and $24.0 \%, 6.0 \%$, and $0 \%$, respectively. The non-resection group of patients ( $\mathrm{n}=184)$ had a median survival of 3.6 months and one-year, 3-year, and 5-year overall survival rates of $13.6 \%$, $1.9 \%$, and $0.6 \%$, respectively. PCC patients who underwent hepatectomy had significantly superior survival when compared to those who had an unresectable tumor. Further, patients with PCC who underwent curative resection had significant better survival than those who did not undergo curative resection. PCC patients with positive microscopic resection after hepatectomy had significantly better survival than those with a macroscopic resection margin (11.4 months versus 5.8 months; $P=0.0012$ ). It is worth noting that patients with an $\mathrm{R} 2$ resection margin had survival rates similar to those of patients without hepatectomy (Table 2 and Figure 1).

Univariate analysis identified carcinoembryonic antigen values more than $5 \mathrm{ng} / \mathrm{mL}$, lymph node positivity, positive microscopic resection, histological tumor grade, and absence of chemotherapy as adversely affecting survival in patients undergoing surgery with a positive resection margin (Table 3). Tumor size, tumor number, vascular, perineural, and lymphatic invasion did not affect survival. Multivariate Cox proportional hazard analysis identified tumor differentiation, negative lymph node metastasis, and chemotherapy to be independently favorable prognostic factors (Table S5 and Figure $2 \mathrm{~A}-\mathrm{C}$ ). 
Table 2 Long term survival of 398 patients with intrahepatic cholangiocarcinoma

\begin{tabular}{|c|c|c|c|c|c|}
\hline & Median (m) & $95 \% \mathrm{Cl}$ of median & I-year (\%) & 3-year (\%) & 5-year (\%) \\
\hline All $(n=398)$ & 7.9 & $6.5-9.2$ & 40.5 & 16.5 & 10.4 \\
\hline \multicolumn{6}{|l|}{ Resection $(n=2 \mid 4)$} \\
\hline Ro $(n=130)$ & 26.1 & 14.9-37.4 & 78.5 & 43.3 & 28.6 \\
\hline $\mathrm{RI}(\mathrm{n}=59)$ & 11.4 & $8.2-14.7$ & 47.5 & 6.8 & 4.5 \\
\hline$R 2(n=25)$ & 5.8 & $4.2-7.3$ & 24.0 & 6.0 & 0.0 \\
\hline Non-resection $(n=184)$ & 3.6 & $3.1-4.2$ & 13.6 & 1.9 & 0.6 \\
\hline \multicolumn{6}{|c|}{ Resection versus non-resection $P<0.000$ I } \\
\hline & & $\begin{array}{l}\text { R0 } \\
<00001\end{array}$ & \multicolumn{2}{|l|}{ RI } & \multirow[t]{2}{*}{$\mathrm{R} 2$} \\
\hline RI & & $<0.0001$ & & & \\
\hline R2 & & $<0.0001$ & \multicolumn{2}{|c|}{0.013} & \\
\hline Non-resection & & $<0.0001$ & \multicolumn{2}{|c|}{$<0.0001$} & 0.092 \\
\hline
\end{tabular}

Note: Bold values indicate significance.

Abbreviation: $\mathrm{Cl}$, confidence interval.

\section{Recurrence pattern}

Recurrences were documented in 89 patients during follow-up at a total of 63 specific sites, as summarized in Table S6. We divided the recurrence sites into three main areas, ie, locoregional, peritoneal, and distant. All recurrences were documented clinically, radiologically, and histologically. Figure S1 illustrates the pattern of recurrence. Overall, 35 patients had recurrences involving a single area, eleven had recurrences involving two areas, and two had recurrences involving all three areas. Thirty-three patients had

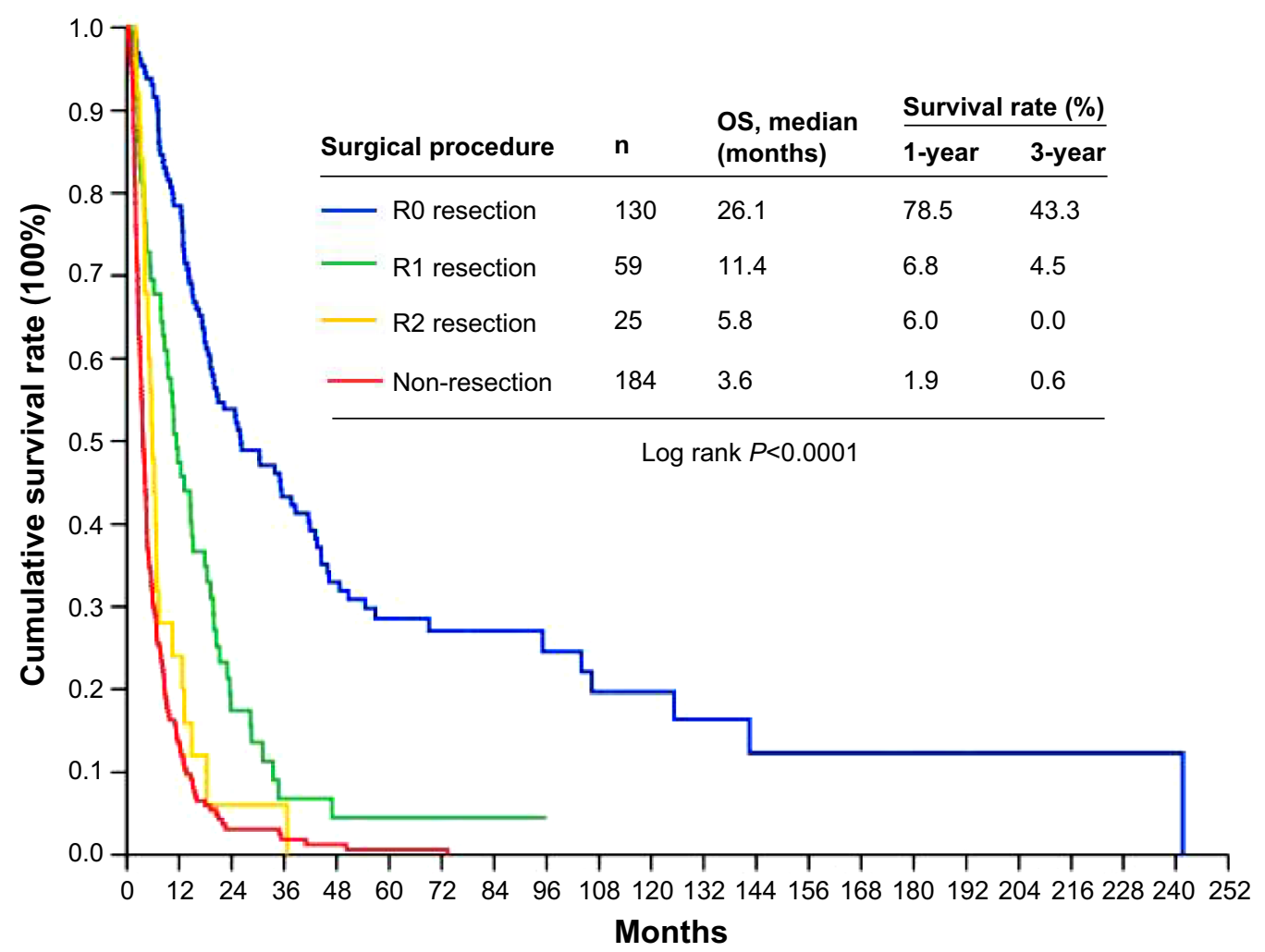

Number at risk

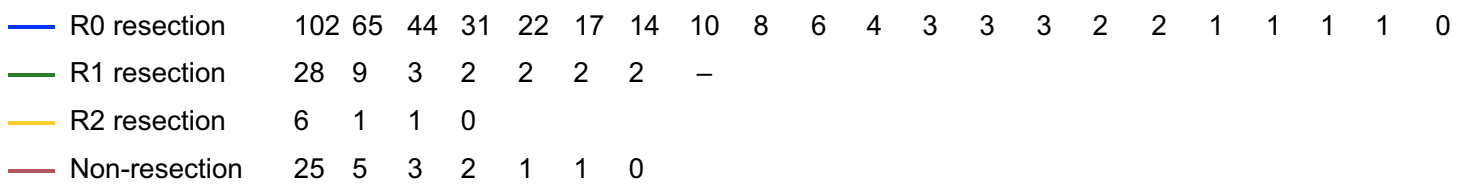

Figure I Difference in overall survival rates of 398 PCC patients divided into R0, RI, and R2 resection groups and a nonresection group. Abbreviations: OS, overall survival; PCC, peripheral cholangiocarcinoma. 
Table 3 Univariate and multivariate analysis of factors influencing the overall survival in resected intrahepatic cholangiocarcinoma with positive resection margin

\begin{tabular}{|c|c|c|c|c|c|c|}
\hline Factors & $(\mathbf{N})$ & $\begin{array}{l}\text { Median survival } \\
\text { (ms) }\end{array}$ & $\begin{array}{l}95 \% \mathrm{Cl} \\
\text { of median }\end{array}$ & $\begin{array}{l}\text { I-year } \\
(\%)\end{array}$ & $\begin{array}{l}\text { 3-year } \\
\text { (\%) }\end{array}$ & $P$-value \\
\hline \multirow[t]{2}{*}{ Age (yrs) } & $\leq 65(62)$ & 8.7 & $5.6-11.8$ & 37.7 & 5.0 & 0.618 \\
\hline & $>65(22)$ & 11.7 & $2.6-20.9$ & 50.0 & 10.1 & \\
\hline \multirow[t]{2}{*}{ Gender } & Male (38) & 10.7 & $4.9-16.5$ & 50.0 & 9.8 & 0.164 \\
\hline & Female (46) & 7.3 & $4.1-10.5$ & 32.6 & 3.2 & \\
\hline \multirow[t]{2}{*}{ CA $19-9(\mathrm{U} / \mathrm{mL})$} & $\leq 37$ (9) & 17.8 & $4.6-31.1$ & 66.7 & 16.7 & 0.110 \\
\hline & $>37(23)$ & 10.8 & $5.0-16.7$ & 47.8 & 7.0 & \\
\hline \multirow[t]{2}{*}{ CEA $(\mathrm{ng} / \mathrm{mL})$} & $\leq 5(34)$ & 11.7 & $8.2-15.2$ & 50.0 & 8.8 & 0.031 \\
\hline & $>5(2 \mathrm{I})$ & 5.8 & $0.0-14.4$ & 33.3 & 0.0 & \\
\hline \multirow[t]{2}{*}{ Tumor size $(\mathrm{cm})$} & $\leq 5(30)$ & 9.3 & $5.6-12.9$ & 36.7 & 0.0 & 0.464 \\
\hline & $>5(30)$ & 6.2 & $0.0-14.1$ & 43.3 & 11.4 & \\
\hline \multirow[t]{3}{*}{ Tumor number } & Single (69) & 9.4 & $6.1-12.7$ & 40.6 & 5.5 & 0.307 \\
\hline & Daughter/satellite (7) & 3.8 & $2.4-5.3$ & 28.6 & 0.0 & \\
\hline & Multiple (8) & 10.5 & $0.0-26.5$ & 50.0 & 25.0 & \\
\hline \multirow[t]{2}{*}{ T stage } & $\mathrm{TI} / \mathrm{T} 2$ (I5) & 14.4 & I.7-27.1 & 53.3 & 6.7 & 0.505 \\
\hline & $\mathrm{T} 3 / \mathrm{T} 4$ (69) & 8.7 & $4.9-12.5$ & 37.7 & 6.6 & \\
\hline \multirow[t]{2}{*}{ Nodal status } & Negative (58) & 10.8 & $8.0-13.6$ & 46.6 & 7.0 & $0.017^{\mathrm{a}}$ \\
\hline & Positive (26) & 5.3 & $3.6-7.0$ & 26.9 & 4.5 & \\
\hline \multirow[t]{2}{*}{ Stage } & $\mathrm{I} / \mathrm{II}(9)$ & 19.9 & $3.8-36.1$ & 66.7 & 0.0 & 0.375 \\
\hline & III/IVA (75) & 8.3 & $4.9-11.6$ & 37.3 & 7.7 & \\
\hline \multirow[t]{2}{*}{ Margin } & $\mathrm{RI}(59)$ & 11.4 & $8.2-14.7$ & 47.5 & 6.8 & 0.013 \\
\hline & R2 (25) & 5.8 & $4.2-7.3$ & 24.0 & 6.0 & \\
\hline \multirow{4}{*}{ Gross type } & IP (15) & 14.4 & $9.8-19.0$ & 60.0 & 0.0 & 0.190 \\
\hline & MF (22) & 10.7 & $0.0-21.7$ & 50.0 & 6.6 & \\
\hline & MF-PI (23) & 5.0 & $3.2-6.8$ & 17.4 & 8.7 & \\
\hline & PI (24) & 10.5 & $6.8-14.1$ & 41.7 & 8.3 & \\
\hline \multirow[t]{4}{*}{ Histological grade } & Well (19) & 19.2 & $10.3-28.1$ & 63.2 & 14.6 & $<0.000 \mathrm{I}^{\mathrm{b}}$ \\
\hline & Moderate (29) & 7.9 & $4.4-11.4$ & 31.0 & 0.0 & \\
\hline & Poor (24) & 5.3 & $4.0-6.6$ & 20.8 & 0.0 & \\
\hline & Others (I2) & 13.2 & $3.3-23.1$ & 66.7 & 16.7 & \\
\hline \multirow[t]{2}{*}{ IHD stones } & No (36) & 10.5 & $6.8-14.3$ & 47.2 & 9.5 & 0.238 \\
\hline & Yes (48) & 7.9 & $4.5-11.3$ & 35.4 & 4.4 & \\
\hline \multirow[t]{2}{*}{ Vascular invasion } & No (65) & 9.3 & $4.6-13.9$ & 43.1 & 6.6 & 0.304 \\
\hline & Yes (19) & 9.4 & $4.8-14.0$ & 31.6 & 5.3 & \\
\hline \multirow[t]{2}{*}{ Lymphatic invasion } & No (59) & 11.4 & $6.6-16.3$ & 47.5 & 5.0 & 0.070 \\
\hline & Yes (25) & 6.3 & $3.4-9.2$ & 24.0 & 8.0 & \\
\hline \multirow[t]{2}{*}{ Perinueral invasion } & No (43) & 9.3 & $3.7-14.8$ & 39.5 & 6.9 & 0.546 \\
\hline & Yes (4I) & 10.2 & $6.9-13.5$ & 41.5 & 5.6 & \\
\hline \multirow[t]{2}{*}{ Chemotherapy } & No (45) & 5.3 & $3.4-7.2$ & 28.9 & 5.5 & $0.024^{c}$ \\
\hline & Yes (39) & 12.7 & $9.1-16.3$ & 53.8 & 7.3 & \\
\hline \multirow[t]{2}{*}{ Radiotherapy } & No (63) & 9.3 & $5.0-13.5$ & 38.1 & 7.3 & 0.979 \\
\hline & Yes (2I) & 11.7 & $3.5-19.9$ & 47.6 & 4.8 & \\
\hline
\end{tabular}

Note: ${ }^{a-c}$ mean significance in cox's proportional hazards analysis, $P=0.007,0.008$, and 0.028 , respectively.

Abbreviations: yrs, years; CA, carbohydrate antigen; CEA, carcinoembryonic antigen; T, tumor; IHD, intrahepatic dust.

locoregional involvement. Distant sites were involved in nine patients. The liver and bile duct were the most common sites of locoregional recurrence. Peritoneal recurrence was detected in 23 patients (Table S6).

\section{Discussion}

Intrahepatic PCC is an aggressive disease with a 5-year survival rate of $25 \%$ even after aggressive surgical resection. ${ }^{2,16,25}$
Our previous study, one of the largest in the world, showed a 5-year survival of $28.6 \%$ after R0 resection. An absence of physical findings, presence of mucobilia, an early-stage tumor, and curative hepatic resection were the four independent prognostic factors contributing to long-term survival. ${ }^{19}$ Among these, the resection margin is the only factor that hepatic surgeons can improve. In this study, we attempted to identify the clinicopathological features and recurrence 
patterns associated with positive surgical margins. All these data can show the clinical effect of a positive surgical margin on overall survival.

The rate of $\mathrm{R} 0$ in hepatic cancers varies from $30 \%$ to $80 \% .^{2,11,12,18,19,22-29} \mathrm{R} 0$ resection is the only way to obtain an acceptable long-term result, and has a 5-year survival rate of $36 \%-54 \% .^{2,12,28,29}$ Lang et al reported 5-year survival of $28 \%$ for 54 PCC patients; however, survival was $48 \%$ for the $\mathrm{R} 0$ resection patients and $0 \%$ for R1/R2 patients. ${ }^{15}$ Similarly, Uenishi et al reported 5-year survival of 39\% for PCC patients with radical resection and $0 \%$ for those with $\mathrm{R} 1$ resection. ${ }^{22}$ In our study, radical resection was achieved in $60.3 \%$ of PCC patients, with a median survival of 31 months for R0 resection compared with 11.4 months for R1 patients and 5.8 months for R2 patients (5-year survival for R0 was $28.6 \%$ versus $0 \%$ for R2; $P<0.05$, Figure 1).
A positive surgical margin was reported in $15 \%-68 \%$ of PCC patients after hepatectomy in different studies. ${ }^{20-22}$ In our cohort, 89 (39.7\%) of 224 patients who underwent hepatectomy had positive resection margins. The liver parenchyma is the most common site for a positive resection margin. An adequate hepatic reserve remnant represents a problem for curative resection and is a possible cause of hepatic failure after hepatectomy. In this case, portal vein embolization is a potential solution. For the bile duct margin, the use of intraoperative frozen sections to determine the extent of the resection margin might help to solve part of the problem.

We used univariate analysis to identify clinicopathological features associated with a positive resection margin, such as the presence of nonpapillary histology $(P=0.050)$, intrahepatic stones $(P=0.001)$, and a higher tumoral T stage $(P<0.001)$. Although intraoperative assessment of the margin was done

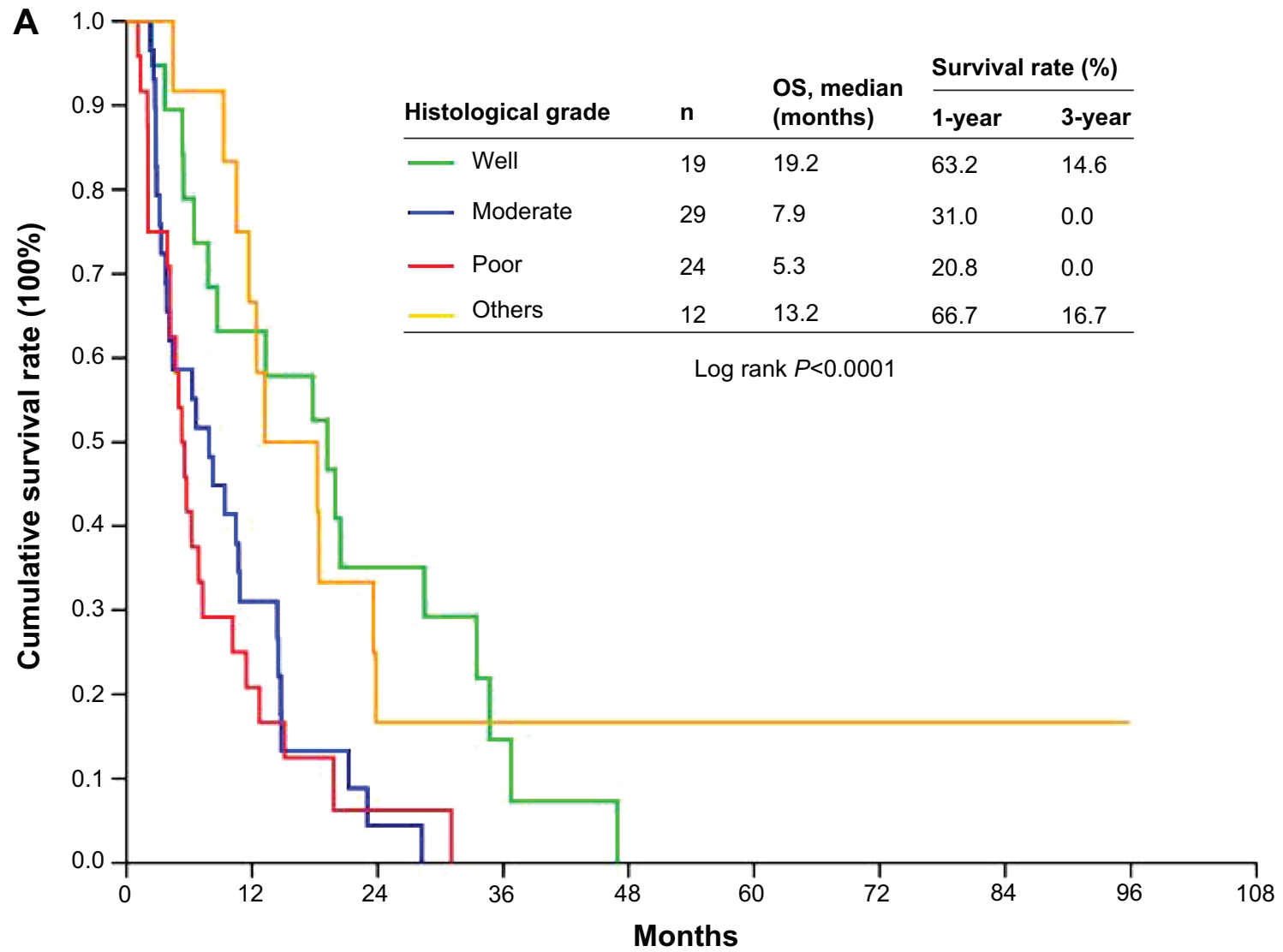

Number at risk

$\begin{array}{ll}- \text { Well } & 12 \\ \text { Moderate } & 9 \\ \text { Poor } & 5 \\ \text { Others } & 8\end{array}$

$\begin{array}{ll}6 & 2 \\ 1 & 0 \\ 1 & 0 \\ 2 & 2\end{array}$
0 0 2

Figure 2 (Continued) 


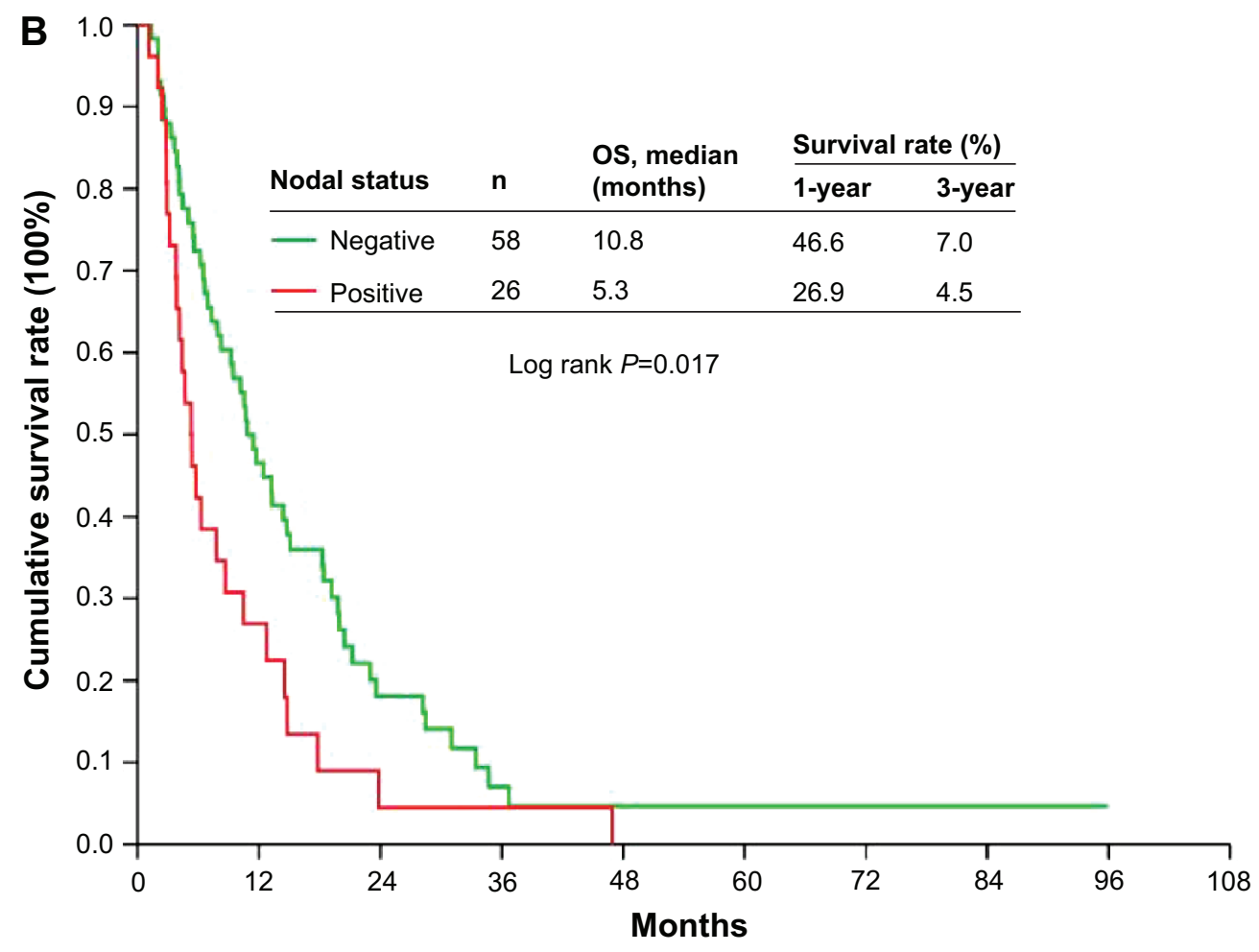

Number at risk

$\begin{array}{ccccccccc}- \text { Negative } & 27 & 9 & 3 & 2 & 2 & 2 & 1 & - \\ \text { - Positive } & 7 & 1 & 1 & 0 & & & \end{array}$

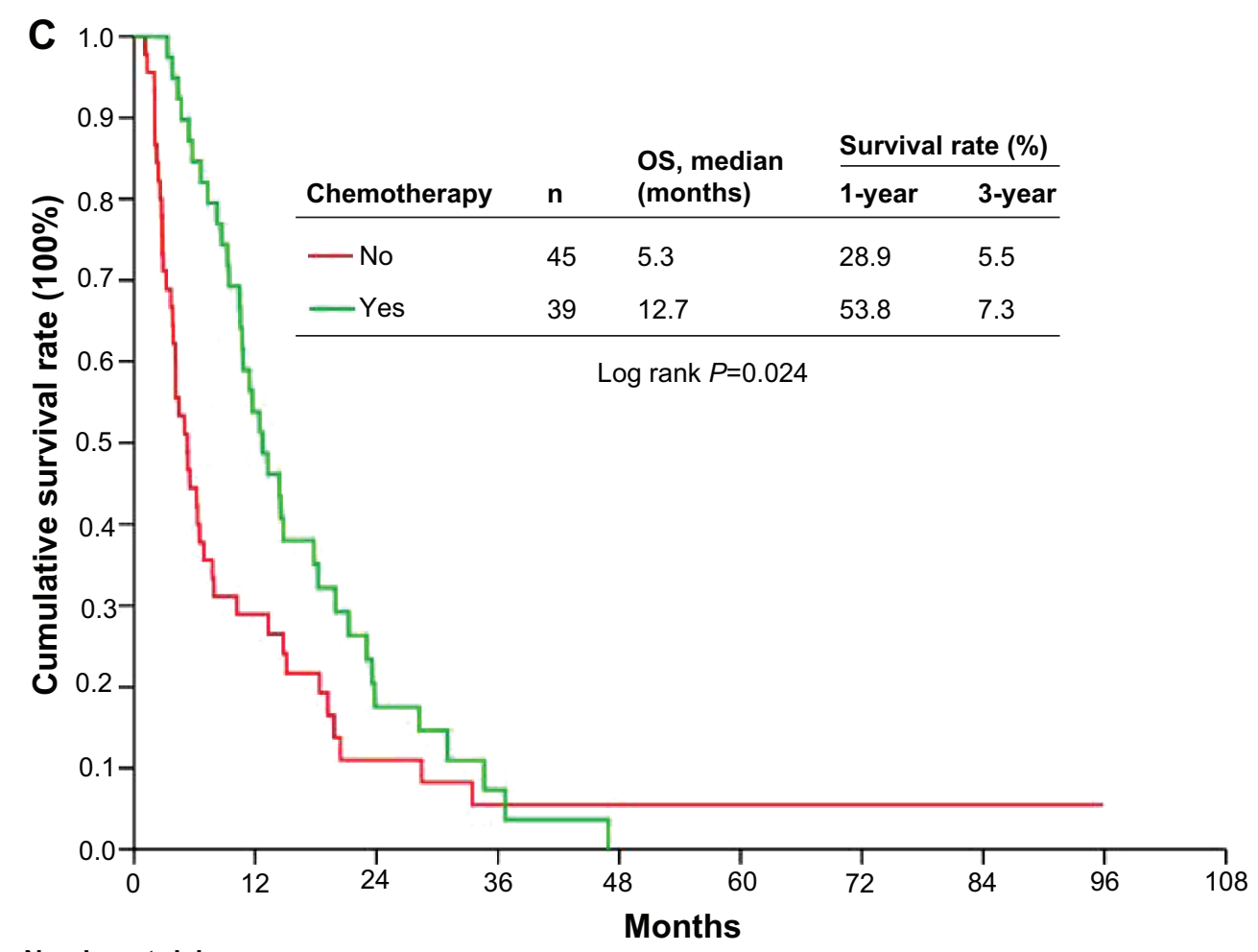

Number at risk

$\begin{array}{lllllllll}\text { No } & 13 & 4 & 2 & 2 & 2 & 2 & 1 & - \\ - \text { Yes } & 21 & 6 & 2 & 0 & & & \end{array}$

Figure 2 Overall survival (OS) rates for 84 peripheral cholangiocarcinoma patients with a positive resection margin based on tumor differentiation (A), nodal status (B), and postoperative chemotherapy (C). 
using ultrasonography, $39.7 \%$ of the patients had a positive resection margin. A positive surgical margin did not correlate with tumor size. Intraductal papillary tumors tend to be well differentiated, with cancer cells confined to the mucosal layer of the affected bile duct and less frequent lymphatic, venous, or perineural involvement. ${ }^{19,27}$ This may explain the low level of margin positivity for intraductal tumors in our series.

Hepatolithiasis was associated with increased margin positivity. Chen et al proposed that hepatolithiasis prevented precise diagnosis of PCC preoperatively, making margin assessment difficult. ${ }^{28}$ It was also reported that a higher $\mathrm{T}$ stage was associated with higher margin positivity. Patients with T3 tumors tended to have more R1 than R2 resections, which can be explained by the frequent presence of intrahepatic metastasis. T4 tumors had a high incidence of $\mathrm{R} 2$ resection. Shimada et al found that the positive margin correlated better with the presence of intrahepatic metastasis than with the size of the tumor. This was attributed to the difficulty in recognizing small multiple tumors during hepatic resection. ${ }^{21}$

PCC patients who undergo curative resection obviously had superior survival when compared with those who had $\mathrm{R} 1$ and R2 resection (median survival of 26.1 months for R0, 11.3 months for R1, and 5.8 months for R2). It is worth noting that patients with $\mathrm{R} 2$ resection had survival similar to that of patients without hepatectomy. The clinical effect of a positive surgical margin is inconclusive. Lang et al, Jan et al, and de Jong et al found a positive surgical margin to be an important prognostic factor; however, the findings of Shimada et al, Tamandl et al, and Farges et al, were inconclusive. . $^{15,19,21,23,24,28}$

Shirai et al found that tumors with a positive resection margin, higher T stage, positive nodal status, less differentiated status, and no chemotherapy contributed to an adverse prognosis. ${ }^{20}$ In contrast with their results, perineural invasion was not found to be a prognostic factor in our study. However, lower histological differentiation grade $(P<0.0001)$, presence of positive lymph nodes $(P<0.0001)$, and absence of chemotherapy $(P=0.0001)$ were three independent adverse prognostic factors (Figure $2 \mathrm{~A}-\mathrm{C}$ ). The median survival for patients with well differentiated, moderately differentiated, and poorly differentiated tumors was 19.2, 7.9, and 5.3 months, respectively, making tumor biology one of the most important predictors for survival (Figure 2A), in agreement with the reports of Yamashita et al and Shirabe et al. ${ }^{29,30}$

We found that patients with a negative lymph node status had a median survival of 10.8 months compared with 5.3 months in patients with a positive status (Figure 2B).
This finding supports the idea that the presence of lymph node metastasis is one of the strongest prognostic predictors. ${ }^{2,21,24,30,31}$ Inoue et al suggested that hepatectomy is contraindicated in the presence of lymph node metastasis at the time of sampling. ${ }^{32}$ On the contrary, Weber et al reported long-term survivors with lymph node metastasis. ${ }^{33}$ Given that preoperative assessment of lymph node involvement is difficult, aggressive lymph node dissection might be the safest approach. However, the role of lymph node dissection is still unclear and needs further investigation.

The effect of chemotherapy in the treatment of PCC is not well defined. Although response rates of $20 \%-30 \%$ have been reported, clinical trials have failed to show consistent benefits. $^{7}$ The Mayo Clinic obtained excellent results with neoadjuvant chemoradiotherapy followed by transplantation for hilar cholangiocarcinoma. ${ }^{34}$ Based on the current literature, patients with good performance status might benefit from chemotherapy. ${ }^{7}$ There are very limited data on the efficacy of chemotherapy for PCC patients. Only a small number of PCC cases, together with extrahepatic cholangiocarcinoma, gall bladder carcinoma, and ampullary carcinoma, have been reported, mainly because of the rarity of these diseases. A variety of confounding factors influence the effect of chemotherapy and complicate the evaluation, such as control of cholangitis, liver function, and performance status. In this article, one of the authors (JSC) used chemotherapy during the study period and achieved a response rate of around $30 \%$ and a median survival of more than 1 year for PCC patients. ${ }^{35-39}$ Key drugs currently available for chemotherapy are gemcitabine, fluoropyrimidines, and platinum-based drugs. Further investigations are required for the development of new agents, such as molecular targeting drugs and combined therapy with surgery. ${ }^{40}$ Although our center has used a variety of chemotherapies for advanced PCC over the last three decades with variable outcomes, use of palliative chemotherapy for PCC with a positive margin after hepatectomy does have a survival benefit (Figure 2C). This result is in agreement with a recent meta-analysis showing that chemotherapy is beneficial for PCC. ${ }^{41}$

We analyzed the recurrence pattern in PCC patients with a positive resection margin, and found that the locoregional area was the most common site of recurrence, followed by the peritoneal and distant areas (Figure S1). In agreement with the results of Weber et al the liver was the most common site of recurrence, followed by the lymph nodes, and distant sites such as the lungs and bone. ${ }^{33}$ All recurrences occurred within a median of 13 months, suggesting that aggressive tumor biology might contribute to the low 
survival rate in PCC patients with positive resection margins. Therefore, postoperative chemotherapy in patients with resected PCC with positive and negative margins should be aggressive.

In conclusion, more advanced tumor stage, a higher T stage, associated hepatolithiasis, and periductal infiltrative tumor growth are the main factors independently associated with a positive resection margin. A positive resection margin has an unfavorable effect on overall survival in PCC patients undergoing hepatectomy. PCC patients with R2 resection had survival similar to that of patients without hepatectomy. In patients with a positive margin, the prognosis was determined by tumor biology, including tumor differentiation and nodal positivity. Chemotherapy was useful for increasing overall survival in these patients.

\section{Author contributions}

All authors contributed toward data analysis, drafting and revising the paper and agree to be accountable for all aspects of the work.

\section{Disclosure}

The authors report no conflicts of interest in this work.

\section{References}

1. Liver Cancer Study Group of Japan. Primary liver cancer in Japan. Clinicopathologic features and results of surgical treatment. Ann Surg. 1990;211:277-287.

2. Uenishi T, Hirohashi K, Kubo S, Yamamoto T, Yamazaki O, Kinoshita H. Clinicopathological factors predicting outcome after resection of mass-forming intrahepatic cholangiocarcinoma. Br J Surg. 2001;88: 969-974.

3. Chen MF, Jan YY, Wang CS, et al. Clinical experience in 20 hepatic resections for peripheral cholangiocarcinoma. Cancer. 1989;64: 2226-2232.

4. Vatanasapt V, Uttaravichien T, Mairiang EO, Pairojkul C, Chartbanchachai W, Haswell-Elkins M. Cholangiocarcinoma in north-east Thailand. Lancet. 1990;335:116-117.

5. Berdah SV, Delpero JR, Garcia S, Hardwigsen J, Le Treut YP. A western surgical experience of peripheral cholangiocarcinoma. $\mathrm{Br} J$ Surg. 1996;83:1517-1521.

6. Chu KM, Lai EC, Al-Hadeedi, et al. Intrahepatic cholangiocarcinoma. World J Surg. 1997;21:301-305.

7. Verslype C, Prenen H, Van Cutsem E. The role of chemotherapy in biliary tract carcinoma. HPB. 2008;10:164-167.

8. Todoroki T, Ohara K, Kawamoto T, et al. Benefits of adjuvant radiotherapy after radical resection of locally advanced main hepatic duct carcinoma. Int J Radiat Oncol Biol Phys. 2000;46:581-587.

9. Gonzalez GD, Gouma DJ, Rauws EA, van Gulik TM, Bosma A, Koedooder C. Role of radiotherapy, in particular intraluminal brachytherapy, in the treatment of proximal bile duct carcinoma. Ann Oncol. 1999;10:215-220.

10. Goldstein RM, Stone M, Tillery GW, et al. Is liver transplantation indicated for cholangiocarcinoma? Am J Surg. 1993;166:768-771.

11. Jeyarajah DR, Klintmalm GB. Is liver transplantation indicated for cholangiocarcinoma? J Hepatobiliary Pancreat Surg. 1998;5:48-51.

12. Meyer CG, Penn I, James L. Liver transplantation for cholangiocarcinoma: results in 207 patients. Transplantation. 2000;69:1633-1637.
13. Yamamoto M, Takasaki K, Yoshikawa T, Ueno K, Nakano M. Does gross appearance indicate prognosis in intrahepatic cholangiocarcinoma? J Surg Oncol. 1998;69:162-167.

14. Weimann A, Varnholt H, Schlitt HJ, et al. Retrospective analysis of prognostic factors after liver resection and transplantation for cholangiocellular carcinoma. Br J Surg. 2000;8:1182-1187.

15. Lang H, Sotiropoulos GC, Fruhauf NR, et al. Extended hepatectomy for intrahepatic cholangiocellular carcinoma (ICC): when is it worthwhile? Single center experience with 27 resections in 50 patients over a 5-year period. Ann Surg. 2005;241:134-143.

16. Ohtsuka M, Ito H, Kimura F, et al. Results of surgical treatment for intrahepatic cholangiocarcinoma and clinicopathological factors influencing survival. Br J Surg. 2002;89:1525-1531.

17. Valverde A, Bonhomme N, Farges O, Sauvanet A, Flejou JF, Belghiti J. Resection of intrahepatic cholangiocarcinoma: a Western experience. J Hepatobiliary Pancreat Surg. 1999;6:122-127.

18. Tamandl D, Herberger B, Gruenberger B, Puhalla H, Klinger M, Gruenberger T. Influence of hepatic resection margin on recurrence and survival in intrahepatic cholangiocarcinoma. Ann Surg Oncol. 2008;15: 2787-2794.

19. Jan YY, Yeh CN, Yeh TS, Hwang TL, Chen MF. Clinicopathological factors predicting long-term overall survival after hepatectomy for peripheral cholangiocarcinoma. World J Surg. 2005;29:894-898.

20. Shirai K, Ebata T, Oda K, Nishio H, Nagino M. Perineural invasion is a prognostic factor in intrahepatic cholangiocarcinoma. World J Surg. 2008;32:2395-2402

21. Shimada K, Sano T, Sakamoto Y, et al. Clinical impact of the surgical margin status in hepatectomy for solitary mass forming type intrahepatic cholangiocarcinoma without lymph node metastasis. J Surg Oncol. 2007;96:160-165.

22. Uenishi T, Hirohashi K, Kubo S, et al. Histological factors affecting prognosis following hepatectomy for intrahepatic cholangiocarcinoma. World J Surg. 2001;25:865-869.

23. Farges O, Fuks D, Boleslawsk E, et al. Influence of surgical margins on outcome in patients with intrahepatic cholangiocarcinoma a multicenter study by the AFC-IHCC-2009 Study Group. Ann Surg. 2011; 254:824-830.

24. de Jong MC, Nathan H, Sotiropoulos GC, et al. Intrahepatic cholangiocarcinoma: an international multi-institutional analysis of prognostic factors and lymph node assessment. J Clin Oncol. 2011;29:3140-3145.

25. Kawarada Y, Mizumoto R. Diagnosis and treatment of cholangiocellular carcinoma of the liver. Hepatogastroenterology. 1990;37:176-181.

26. Weinbren K, Mutum SS. Pathologic aspects of cholangiocarcinoma. J Pathol. 1983;139:217-238.

27. Yeh CN, Jan YY, Yeh TS, Hwang TL, Chen MF. Hepatic resection of the intraductal papillary type of peripheral cholangiocarcinoma. Ann Surg Oncol. 2004;11:606-611.

28. Chen MF, Jan YY, Jeng LB, et al. Intrahepatic cholangiocarcinoma in Taiwan. J Hepatobiliary Pancreat Surg. 1999;6:136-141.

29. Yamashita Y, Taketomi A, Morita K, et al. The impact of surgical treatment and poor prognostic factors for patients with intrahepatic cholangiocarcinoma: retrospective analysis of 60 patients. Anticancer Res. 2008;28:2353-2360.

30. Shirabe K, Mano Y, Taketomi A, et al. Clinicopathological prognostic factors after hepatectomy for patients with mass-forming type intrahepatic cholangiocarcinoma: relevance of the lymphatic invasion index. Ann Surg Oncol. 2010;17:1816-1822.

31. Yedibela S, Demir R, Zhang W, Meyer T, Hohenberger W, Schönleben F. Surgical treatment of mass forming intrahepatic cholangiocarcinoma: an 11-year Western single center experience in 107 patients. Ann Surg Oncol. 2009;16:404-412.

32. Inoue $\mathrm{K}$, Makuuchi $\mathrm{M}$, Takayama $\mathrm{T}$, et al. Long term survival and prognostic factors in surgical treatment in mass forming type cholangiocarcinoma. Surgery. 2000;127:498-505.

33. Weber SM, Jarnagin WR, Klimstra D, et al. Intrahepatic cholangiocarcinoma: resectability, recurrence pattern, and outcomes. $J$ Am Coll Surg. 2001;193:384-391. 
34. Rea DJ, Heimbach JK, Rosen CB, et al. Liver transplantation with neoadjuvant chemoradiation is more effective than resection for hilar cholangiocarcinoma. Ann Surg. 2005;8:242-451.

35. Chen JS, Jan YY, Lin YC, Wang HM, Chang WC, Liau CT. Weekly $24 \mathrm{~h}$ infusion of high-dose 5-fluorouracil and leucovorin in patients with biliary tract carcinomas. Anticancer Drugs. 1998;9: 393-397.

36. Chen JS, Lin YC, Jan YY, Liau CT. Mitomycin C with weekly 24-h infusion of high-dose 5-fluorouracil and leucovorin in patients with biliary tract and periampullar carcinomas. Anticancer Drugs. 2001;12: 339-343.

37. Chen JS, Yang TS, Lin YC, Jan YY. A phase II trial of tegafur-uracil plus leucovorin (LV) in the treatment of advanced biliary tract carcinomas. Jpn J Clin Oncol. 2003;33:353-356.
38. Hsu C, Shen YC, Yang CH, et al. Weekly gemcitabine plus 24-h infusion of high-dose 5-fluorouracil/leucovorin for locally advanced or metastatic carcinoma of the biliary tract. Br J Cancer. 2004;90:1715-1719.

39. Chen JS, Chao Y, Yang TS, et al. A phase II trial of biweekly oxaliplatin with simplified schedule of 48-h infusion of high-dose 5-fluorouracil and leucovorin for advanced biliary tract carcinoma. Cancer Chemother Pharmacol. 2009;65:151-157.

40. Gruenberger B, Schueller J, Heubrandtner U, et al. Cetuximab, gemcitabine, and oxaliplatin in patients with unresectable advanced or metastatic biliary tract cancer: a phase 2 study. Lancet Oncol. 2010;11: 1142-1148.

41. Horgan AM, Amir E, Walter T, Knox JJ. Adjuvant therapy in the treatment of biliary tract cancer: a systematic review and meta-analysis. J Clin Oncol. 2012;30:1934-1940. 


\section{Supplementary materials}

Table SI Type of hepatic resection in 224 patients with intrahepatic cholangiocarcinoma

\begin{tabular}{|c|c|c|}
\hline Surgical procedure & Case number & $\%$ \\
\hline Left hepatectomy & $138 / 224$ & 61.6 \\
\hline Segment I, 2, 3, 4 & 7 & \\
\hline Segment I, 2, 3, 4+ BR & I & \\
\hline Segment 2, 3, 4 & 74 & \\
\hline Segment 2, 3, $4+B R$ & 2 & \\
\hline Segment I, 2, 3 & I & \\
\hline Segment 2, 3 & 45 & \\
\hline Segment I, 4 & 1 & \\
\hline Segment I & I & \\
\hline Segment 3 & I & \\
\hline Segment 4 & 5 & \\
\hline Right hepatectomy & $5 I / 224$ & 22.8 \\
\hline Segment $4,5,6,7,8$ & 3 & \\
\hline Segment $4,5,6,7,8+B R$ & 2 & \\
\hline Segment $5,6,7,8$ & 19 & \\
\hline Segment $5,6,7,8+B R$ & 4 & \\
\hline Segment $5,6,7$ & 3 & \\
\hline Segment 6, 7, 8 & I & \\
\hline Segment 4,5 & 5 & \\
\hline Segment 5, 6 & 4 & \\
\hline Segment 6, 7 & 6 & \\
\hline Segment 7.8 & I & \\
\hline Segment 5 & 2 & \\
\hline Segment 6 & I & \\
\hline Bilateral hepatectomy & $24 / 224$ & 10.7 \\
\hline Segment I, 2, 4, 5, 8 & I & \\
\hline Segment I, 2, 3, 4, 5, $8+$ BR & I & \\
\hline Segment I, 5, 6, 7, 8 & I & \\
\hline Segment I, 5, 6, 7, $8+B R$ & I & \\
\hline Segment 2, 3, 4, 5, 8 & 2 & \\
\hline Segment 4, 5, 6, 7, 8 & I & \\
\hline Segment 2, 3, 4, 6 & 1 & \\
\hline Segment 2, 3, 4, 8 & I & \\
\hline Segment 2, 3, 5 & I & \\
\hline Segment 3, 5, 6 & I & \\
\hline Segment 4, 5, 6 & 3 & \\
\hline Segment 4, 5, 8 & 7 & \\
\hline Segment I, 6 & I & \\
\hline Segment 3, 8 & I & \\
\hline Partial hepatectomy & $11 / 224$ & 4.9 \\
\hline
\end{tabular}

Abbreviation: $\mathrm{BR}$, bile duct resection.
Table S2 Resection margin involved in intrahepatic cholangiocarcinoma

\begin{tabular}{ll}
\hline & (n=89) \\
\hline Liver tissue (main part) & $6 \mathrm{I}(68.5)$ \\
LT only & 36 \\
LT + HD & 15 \\
LT + ST & 8 \\
LT + HD + ST & 2 \\
Hepatic duct (main part) & $29(32.6)$ \\
HD only & $1 \mathrm{I}$ \\
HD + LT & 15 \\
HD + LT + ST & 2 \\
HD + ST & 1 \\
Soft tissue (main part) & $27(30.3)$ \\
ST only & 16 \\
ST + HD & 1 \\
ST + LT & 8 \\
ST + LT + HD & 2
\end{tabular}

Note: Values in parentheses are percentages.

Abbreviations: LT, liver tissue; HD, hepatic duct tissue; ST, soft tissue.

Table S3 Multiple variance analysis of multinomial logistic regression in the $\mathrm{RI}$ resection group compared with $\mathrm{R} 0$ used as reference

\begin{tabular}{|c|c|c|c|c|c|}
\hline \multirow[t]{2}{*}{ RI/R0 } & \multirow[t]{2}{*}{ B } & \multirow[t]{2}{*}{ OR } & \multicolumn{2}{|c|}{$95 \% \mathrm{Cl}$ of OR } & \multirow[t]{2}{*}{$P$-value } \\
\hline & & & Lower & Upper & \\
\hline \multicolumn{6}{|l|}{ Factors } \\
\hline \multicolumn{6}{|l|}{ IHD stones } \\
\hline With/without & 1.101 & 3.006 & $\mathrm{I} .446$ & 6.249 & 0.003 \\
\hline \multicolumn{6}{|l|}{ Gross type } \\
\hline MF/IP & -0.991 & 0.371 & 0.121 & $1.14 \mid$ & 0.084 \\
\hline MF-PI/IP & -0.405 & 0.667 & 0.250 & 1.779 & 0.418 \\
\hline $\mathrm{PI} / \mathrm{IP}$ & -0.605 & 0.546 & 0.165 & 1.813 & 0.323 \\
\hline \multicolumn{6}{|l|}{ T stage } \\
\hline T3, 4/TI, 2 & 0.172 & 1.187 & 0.346 & 4.080 & 0.785 \\
\hline \multicolumn{6}{|l|}{ Staging } \\
\hline III, IV/I, II & 2.081 & 8.014 & 2.163 & 29.688 & 0.002 \\
\hline
\end{tabular}

Note: Bold values indicate significant association.

Abbreviations: $\mathrm{Cl}$, confidence interval; OR, odds ratio; IHD, intrahepatic duct; IP, intraductal papillary; MF, mass-forming type; IP, intra-ductal papillary type; T, tumor. 
Table S4 Multiple variances analysis of multinomial logistic regression of the RI and R2 resection group compared with R0 as reference

\begin{tabular}{|c|c|c|c|c|c|}
\hline \multirow[t]{2}{*}{$\mathbf{R I}+\mathbf{R} 2 / \mathbf{R} \mathbf{0}$} & \multirow[t]{2}{*}{ B } & \multirow[t]{2}{*}{ OR } & \multicolumn{2}{|c|}{$95 \% \mathrm{Cl}$ of OR } & \multirow[t]{2}{*}{$P$-value } \\
\hline & & & Lower & Upper & \\
\hline \multicolumn{6}{|l|}{ Factors } \\
\hline \multicolumn{6}{|c|}{ Associated with IHD stones } \\
\hline With/without & 1.060 & 2.887 & 1.474 & 5.654 & 0.002 \\
\hline \multicolumn{6}{|l|}{ Gross type* } \\
\hline MF/IP & -0.687 & 0.503 & 0.172 & 1.474 & 0.210 \\
\hline MF-PI/IP & -0.222 & 0.801 & 0.308 & 2.087 & 0.650 \\
\hline $\mathrm{PI} / \mathrm{IP}$ & -0.075 & 0.928 & 0.302 & 2.852 & 0.896 \\
\hline \multicolumn{6}{|l|}{ T stage* } \\
\hline T3, 4/TI, 2 & 0.485 & 1.624 & 0.488 & 5.404 & 0.429 \\
\hline \multicolumn{6}{|l|}{ Staging* } \\
\hline III, IV/I, II & 1.998 & 7.376 & 2.027 & 26.846 & 0.002 \\
\hline
\end{tabular}

Note: *Maximum likelihood estimation does not exist when quasi-complete separation of the factor occurs. Bold values indicate significant association.

Abbreviations: $\mathrm{Cl}$, confidence interval; OR, odds ratio; IHD, intrahepatic duct; IP, intraductal papillary; T, tumor.

Table S5 Cox's proportional hazards analysis

\begin{tabular}{lll}
\hline Factors & Hazard ratio (95\% Cl) & P-value \\
\hline CEA (>5/ $\leq 5 \mathrm{ng} / \mathrm{mL})$ & & 0.459 \\
Nodal status (positive/negative) & $2.372(1.269-4.433)$ & 0.007 \\
Margin & & 0.086 \\
Histological grade & & \\
$\quad$ Moderate/well & $3.06 \mathrm{I}(\mathrm{I} .336-7.012)$ & 0.008 \\
$\quad$ Poor/well & $2.929(\mathrm{I} .268-6.763)$ & 0.012 \\
$\quad$ Others/well & $1.275(0.504-3.226)$ & 0.609 \\
Chemotherapy (no/yes) & $1.932(1.092-3.48 \mathrm{I}-4.122)$ & 0.028 \\
\hline
\end{tabular}

Abbreviations: CEA, carcinoembryonic antigen; $\mathrm{Cl}$, confidence interval.
Table S6 Specific sites of recurrence within the three areas

\begin{tabular}{ll}
\hline Locoregional & 33 \\
Liver and/or bile duct & 33 \\
Distant & 9 \\
Scalp & $\mathrm{I}$ \\
Neck LN & 2 \\
Lung & $\mathrm{I}$ \\
Bone & $\mathrm{I}$ \\
Spine & $\mathrm{I}$ \\
Abdominal wall & 3 \\
Intra-abdominal carcinomatosis & $21(42 \%)$
\end{tabular}

Abbreviation: LN, lymph nodes.

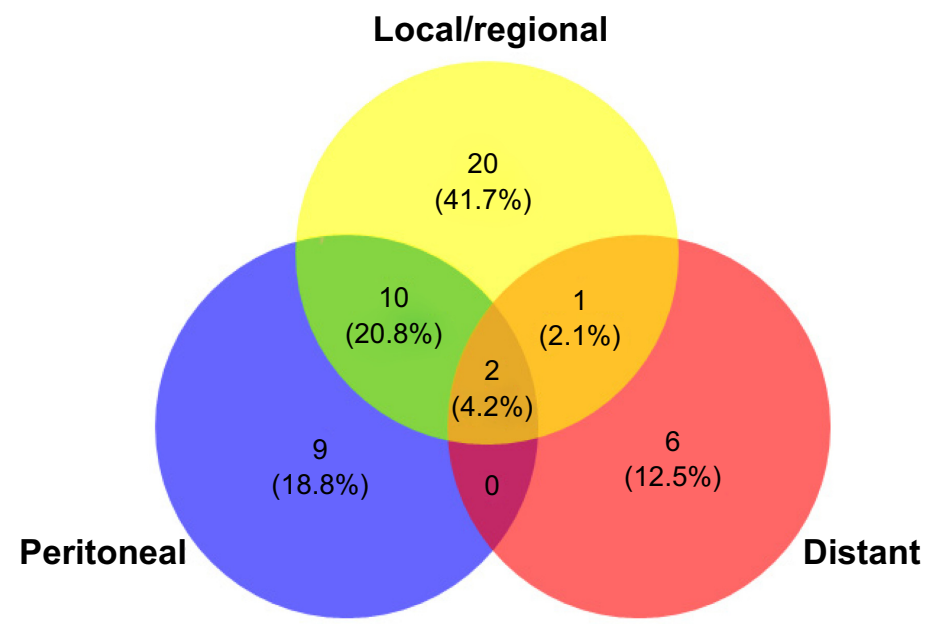

Figure SI Plot of recurrence patterns in 63 peripheral cholangiocarcinoma patients with a positive resection margin and clinically, radiologically, or histologically documented recurrences.

Drug Design, Development and Therapy

\section{Publish your work in this journal}

Drug Design, Development and Therapy is an international, peerreviewed open-access journal that spans the spectrum of drug design and development through to clinical applications. Clinical outcomes, patient safety, and programs for the development and effective, safe, and sustained use of medicines are a feature of the journal, which

\section{Dovepress}

has also been accepted for indexing on PubMed Central. The manuscript management system is completely online and includes a very quick and fair peer-review system, which is all easy to use. Visit $\mathrm{http}: / /$ www.dovepress.com/testimonials.php to read real quotes from published authors.

Submit your manuscript here: http://www.dovepress.com/drug-design-development-and-therapy-journal 